Stijn Reijnders

Schuldig landschap. Over de toeristische aantrekkingskracht van Baantjer, Wallander en Inspector Morse

De opnamelokaties van tv-detectives genieten een toenemende populariteit onder toeristen. In dit artikel wordt, op basis van een tekstuele analyse van 'Baantjer', 'Inspector Morse' en 'Wallander', onderzocht welke inhoudelijke kenmerken van deze tv-detectives mogelijk als 'trigger' fungeren. Uit de analyse blijkt dat plaats en beweging een centrale rol vervullen binnen de narratieve structuur van dit genre. Door zelf de lokaties te bezoeken, kunnen toeristen het spoor nalopen van hun geliefde detective om aldaar, vanuit een veilige positie, tijdelijk op te gaan in het schemergebied tussen fictie en werkelijkheid.

Reijnders, S. (2009). Schuldig landschap. Over de toeristische aantrekkingskracht van Baantjer, Wallander en Inspector Morse. Tijdschrift voor Communicatiewetenschap 37(2): 118-132. 


\section{Schuldig landschap. Over de toeristische aantrekkingskracht van Baantjer, Wallander en Inspector Morse}

We understand a place and a landscape through the historical and personal narratives that are marked out within it and that give that place a particular unity.

- Jeff E. Malpas (1999: 186)

Het stikt hier van de schuld, boom voor boom.

- Armando (1998: 10)

\section{Inleiding}

Wie op een mooie zomerdag Exeter College bezoekt, een van de oudste colleges van Oxford, loopt grote kans een groep toeristen tegen het lijf te lopen. Op zich is dat geen unicum: de meeste colleges trekken een geregelde stroom toeristen aan. Maar de aandacht van deze bezoekers gaat niet zozeer uit naar de fraaie, neogotische kapel, of naar het uitzicht op Radcliffe Square. De fotocamera's zijn allemaal gericht op een hoek van het gazon: op een schijnbaar betekenisloos stukje grasveld. Opvallend is dat het gangbare geklets van toeristen heeft plaatsgemaakt voor een gewijde stilte, waarin slechts het klikken van de camera's hoorbaar is. Wat wil het geval? Het is precies op deze plaats dat Inspector Morse - het centrale karakter van de gelijknamige tv-serie getroffen werd door een hartaanval. In de laatste aflevering van deze wereldwijd populaire detective was te zien hoe Inspector Morse neerzakte, precies híer op het gazon in Exeter College, om enkele uren later te overlijden in het nabijgelegen ziekenhuis. ${ }^{1}$

\section{De tv-detective tour}

De Inspector-Morse Tour vormt al meer dan tien jaar een van de meest populaire tours in Oxford. Ondanks het feit dat de serie al enkele jaren geleden is beëindigd, melden zich jaarlijks nog steeds duizenden toeristen aan om in de voetsporen te treden van de wat sombere, melancholische Inspector Morse en zijn hulpje Lewis. De tour leidt de toeristen in circa twee uur langs de belangrijkste opnamelocaties in het centrum van Oxford, variërend van de fictieve plaatsen delict tot de favoriete pubs van Morse en 
Lewis. Op sommige locaties wordt de band met Morse zichtbaar in ere gehouden. Zo heeft het Randolph Hotel een speciale 'Morse-bar' ingericht, waarbij de wanden zijn gedecoreerd met foto's van de acteurs in gezelschap van Colin Dexter, de auteur van de Morse-serie.

De Inspector Morse Tour is geen alleenstaand geval. In andere steden worden soortgelijke tours georganiseerd. Zo heeft Amsterdam zijn eigen Baantjer-tour, georganiseerd door een lokale onderneming. Het betreft hier een wandeling over de Wallen, waarbij de toerist verschillende locaties uit de populaire Baantjer tv-serie aandoet. Per jaar maken tienduizenden toeristen uit Nederland, België en Frankrijk op deze manier kennis met de binnenstad van Amsterdam. Ystad, een klein stadje in het zuiden van Zweden, vormt sinds enige jaren het decor voor de detective-serie Wallander en is daardoor uitgegroeid tot een belangrijke trekpleister. Toeristen schrijven zich massaal in voor de semi-commerciële Wallander-tour, bezoeken de Wallander-filmstudio's of verkennen "Wallander's Ystad" te voet aan de hand van een speciaal ontwikkeld Wallander-plattegrond. Na afloop kunnen zij in de lokale Konditori een Wallander-gebakje nuttigen, precies aan hetzelfde tafeltje als waar - naar verluidt de inspecteur altijd pleegt te zitten. Bezien vanuit het perspectief van het lokale toeristenbureau, vormt Wallander een unieke kans om de eigen stad en streek te promoten.

Soms is er niet zozeer sprake van een vaste tour, als wel van een eenmalig of jaarlijks terugkerend evenement. Zo werd in de Belgische stad Halle in oktober 2007 een "Witse-speurtocht" gehouden, naar aanleiding van de tv-detective Witse. Amsterdam kent, naast de wekelijkse Baantjer-tour, ook een speciale Baantjer-dag, die bestaat uit filmvertoningen, optredens van de fanfare en een zogenaamde 'boevenborrel'. In Gent, decor van de politie-serie Flikken, wordt dit jaar voor de tiende keer de "Flikken-dag" georganiseerd: een grootschalig evenement dat is gebaseerd op een samenwerking tussen de publieke omroep, de stad Gent, de lokale politie en commerciële veiligheidsdiensten. De tienduizenden bezoekers van de "Flikken-dag" worden getracteerd op een mix van "Flikken-spelen", meet-and-greets met de acteurs uit de serie, parades, straatoptredens en diverse demonstraties van hulp- en veiligheidsdiensten.

Dat toeristen worden aangetrokken door een fictieve detective, is strikt genomen geen nieuw verschijnsel. Een vroeg voorbeeld hiervan kan gevonden worden in de Britse “oer-detective" Sherlock Holmes, wiens vermeend huisadres - Baker Street $221^{\mathrm{b}}-\mathrm{al}$ 
aan het begin van de $20^{\text {ste }}$ eeuw bezoekers trok (Wheeler, 2003). Meer in het algemeen sluiten de tv-detective tours aan op een langer bestaande traditie van literair toerisme. De Britse literatuurwetenschapper Nicola Watson beschrijft in The Literary Tourist (2006) hoe in de negentiende eeuw een fascinatie was ontstaan met de graven en geboortehuizen van bekende schrijvers, evenals met de settings die zij in hun werken beschreven: het Statford-upon-Avon van Shakespeare, het Abbotsford van Sir Walter Scott en het Haworth van de Brontë zusters (cf. Seaton, 1998; Hardyment, 2000). Desondanks onderscheiden de tv-detective tours zich wat betreft schaal duidelijk van hun historische voorgangers. Het literair toerisme uit de negentiende eeuw beperkte zich tot een kleine groep literatuurliefhebbers. De hedendaagse tv-detective tours trekken stuk voor stuk tientallen duizenden toeristen per jaar. Niet langer is sprake van een niche activiteit, maar van een wijd verspreid fenomeen. Tv-detectives vormen voor veel mensen het kader waarbinnen ze een nieuwe stad als Oxford, Amsterdam of Ystad leren kennen.

Weinig is bekend over de oorzaak van deze toenemende populariteit. Onder invloed van postmoderne filosofieën over hyperrealiteit (Baudrillard, 1981) en deterritorialisering (Deleuze \& Guattari, 1988) is lange tijd voornamelijk de nadruk gelegd op het virtuele karakter van onze mediacultuur. Door de overvloed aan mediabeelden zou de postmoderne mens geen onderscheid meer kunnen maken tussen wat werkelijk is en wat niet, zo wordt betoogd. Sterker nog: de virtuele mediawereld zou zelf het belangrijkste referentiekader zijn geworden. Mensen zouden bijvoorbeeld niet meer op reis gaan, maar een "virtueel toerisme" bedrijven door televisie te kijken (Gibson, 2006). Vanuit deze gangbare theoretische modellen is het lastig om te verklaren waarom mensen sowieso de moeite nemen, om naar een plaats toe te reizen waar zij al mee bekend zijn uit de media (Rojek, 1993a: 69-72).

Desalniettemin is de aandacht voor tours gebaseerd op tv-series of films in de laatste jaren wel groeiende. Zo is onder meer geschreven over de toeristische aantrekkingskracht van de set van Coronation Street in de Granada Studio's nabij Manchester (Couldry, 2000) en over de Manhattan TV Tour in New York (Torchin, 2002). Andere onderzoekers hebben zich gericht op: de populariteit van Blade Runner in Los Angeles (Brooker, 2005), Braveheart in Schotland (Edensor, 2005), X-files, Smallville en Battlestar Galactica in Vancouver (Brooker, 2007), Harry Potter-locaties in de UK (Iwashita, 2006), James Bond-locaties wereldwijd (Reijnders, 2010) en 
opnamelocaties van Lord of the Rings in Nieuw-Zeeland (Beeton, 2005; Tzanelli, 2004).

In enkele studies is ook aandacht besteed aan de effecten van deze vorm van toerisme op de lokale gemeenschap. Mordue (2001) interviewde bijvoorbeeld de inwoners van Goathland, nadat dit dorp was uitgegroeid tot een toeristische hotspot door toedoen van de tv-serie Heartbeat. Vergelijkbaar is de studie van Beeton (2005: 123-129) naar de effecten van toerisme in Barwond Heads, het Australische dorp dat als achtergrond diende voor de populaire speelfilm Sea Change.

Bovenstaande studies hebben stuk voor een stuk een belangrijke bijdrage geleverd aan onze kennis over dit nieuwe onderzoeksgebied. Toch is nog weinig tot niets bekend over de rol en betekenis van de mediaproducten zelf. Welke inhoudelijke kenmerken van een tv-serie werken als een trigger en dagen kijkers uit tot het bezoeken van de opnamelokaties? Kennis over dit onderwerp beperkt zich op dit moment tot het niveau van suggesties (cf. Beeton, 2003: 25). Zo stelt Cohen (1986) dat een film waarschijnlijk pas tot toerisme leidt indien de setting duidelijk op de voorgrond aanwezig is. Volgens Riley \& Van Dooren (1992) zou de natuurlijke omgeving waarin het verhaal zich afspeelt ook een belangrijke rol moeten spelen in de karakter-ontwikkeling van het hoofdpersonage. Een laatste suggestie wordt geboden door Couldry (2000), die stelt dat de populariteit van de set van Coronation Street mogelijk voortkomt uit het gegeven dat de serie al een lange tijd loopt en regionale identiteit een belangrijke rol speelt in de verhaallijn.

Ook als we te raden gaan bij studies die zich specifiek richten op literaire of tvdetectives, vinden we geen antwoord op bovenstaande vragen. De bestaande kennis over detectives beperkt zich tot de historische ontwikkeling van dit genre (Roosendaal, 2002; Knight, 2004; Siegel, 1993; Symons, 1992; Mandel, 1984) en haar ideologische betekenis (Pyrhönen, 1994: 81-114; Davis, 2001; Gramsci, 1985: 369-374; Knight 1980 in het bijzonder op het niveau van gender (Betz, 2006; Markozwitz, 2004; Munt, 1994; Thomas, 1995). Ook aan de (re-)constructie van nationale ideologieën in het detectivegenre is herhaaldelijk aandacht besteed (Mukherjee, 2003; Reitz, 2004). In beide gevallen blijft het belang van plaats en lokalisering echter onderbelicht, enkele sporadische uitzonderingen daargelaten (Hausladen, 1996; Craig, 1998; McManis, 1978).

\section{Procedure}


Om tot een antwoord te komen op bovenstaande vraag, wordt in dit artikel een internationale vergelijking gemaakt van drie populaire tv-detectives. Geselecteerd zijn drie series die hebben geleid tot de grootste toeristenstromen binnen hun eigen taalgebied: Inspector Morse, Wallander en Baantjer. Alhoewel er ook tours worden georganiseerd op basis van andere genres, zoals komedies en tv-drama, beperkt dit artikel zich tot een vergelijking van drie tv-detectives. Deze beperking maakt het mogelijk om aandacht te besteden aan de meer algemene genrekenmerken die kijkers kunnen motiveren tot het bezoeken van de opnamelokaties.

De Britse ITV-productie Inspector Morse is de best bekeken tv-detective wereldwijd. Volgens schattingen hebben meer dan één miljard mensen wel eens een fragment van deze serie voor ogen gehad (Adams, 2007). In totaal bestaat Inspector Morse uit 33 afleveringen, voor het eerst uitgezonden in de periode 1987-2000. De Zweedse productie Wallander bestaat uit 22 afleveringen, geproduceerd tussen 1994 en 2006 met wisselende acteurs en door wisselende productiemaatschappijen. Wallander geniet met name een grote populariteit in Zweden, Duitsland en Nederland, maar op het moment van schrijven wordt tevens de hand gelegd aan een Britse adaptatie van deze serie. De tv-detective Baantjer tot slot is een Nederlandse Endemol-productie, bestaande uit 123 afleveringen, voor het eerst uitgezonden tussen 1995 en 2006. Baantjer staat bekend als de best bekeken Nederlandse tv-serie van het afgelopen decennium, en is tevens uitgezonden in België en Frankrijk. De afleveringen van Baantjer duren circa drie kwartier; twee keer zo kort als een gemiddelde aflevering van Inspector Morse of Wallander. Alhoewel de drie detectives van elkaar verschillen op het niveau van setting en narratieve complexiteit, volgen zij alledrie hetzelfde, bekende stramien van de klassieke detective: elke aflevering is opgebouwd rond de oplossing van een moordzaak, waarbij de kijker gaandeweg dezelfde informatie krijgt als de detective. Van elke serie is een willekeurige selectie gemaakt van zes afleveringen. ${ }^{2}$ Deze selectie, bestaande uit totaal circa 27 uur beeldmateriaal, is bekeken in vier blokken van elk zeven uur. Hierbij zijn in een logboek aantekeningen gemaakt. Centraal stond de vraag: op welke wijze wordt het landschap weergegeven en welke narratieve functie vervullen deze beelden voor de rest van het verhaal? Hoe zijn deze representaties gerelateerd aan een meer algemene populaire cultuur? Na afloop zijn de aantekeningen uit het logboek met elkaar vergeleken. Door de overeenkomsten en verschillen uitvoerig met elkaar te vergelijken, is stapsgewijs toegewerkt naar de analyse. Ter illustratie: tijdens de viewings werd opgemerkt dat de detectives zeer regelmatig in 
beeld worden gebracht terwijl zij door de stad lopen of in hun auto door het landschap rijden, een observatie die resulteerde in de analytische categorie 'beweging'.

\section{Couleur locale}

Op de beeldbuis verschijnt een half bewolkte hemel, met daaronder korenvelden, zo ver als het oog reikt. Enkele bomen staan verlaten tussen de akkers. Op het volgende beeld is te zien hoe twee kinderen over een bospad fietsen. Ze zijn op weg naar een oude boerderij, verscholen in het glooiende landschap. De kinderstemmen hebben iets onschuldigs, maar de begeleidende pianomuziek en het gehinnik van een paard geven de setting iets dreigends mee. Die verwachting blijkt waarheid, wanneer de kinderen in de donkere stal het lijk vinden van de paardenhouder.

Met deze beelden opent de Wallander-aflevering 'Het zwakke punt'. Andere afleveringen hebben een soortgelijke opening. We zien velden en akkers die zich uitstrekken tot aan de einder, kronkelende landweggetjes, een verlaten strand, of donkere wolken die vanuit zee komen aanwaaien. Soms opent een aflevering met een beeld van Ystad, het provinciestadje in Zuid-Zweden dat het decor vormt voor de Wallander-reeks. Ook deze openingsbeelden hebben veel weg van een ansichtkaart: ze tonen een wijds uitzicht, met een kerktoren en gevels van oude huisjes die scherp afsteken tegen een helderblauwe hemel. Aan de rand van het stadje is de zee al zichtbaar.

Dat elke aflevering begint met een overzichtsbeeld van de omgeving is niet uniek voor Wallander. Hetzelfde treedt op bij de andere detectives. De meeste afleveringen van Inspector Morse openen bijvoorbeeld met een panorama van Oxford, waarbij de eeuwenoude colleges en kerken uitsteken tussen de daken van oud-Engelse woonhuizen. Aan de horizon tekenen de licht glooiende heuvels van Oxfordshire zich af. Ook Baantjer opent steevast met een vogelperspectief van Amsterdam in de vroege morgen, met op de voorgrond de herkenbare trap- en klokgevels van de Amsterdamse binnenstad.

Het betreft hier een bekende filmische handeling. Door te openen met een wide shot van de omgeving, eventueel gecombineerd met een pan (een geleidelijke draaiing van de camera), wordt de kijker geïntroduceerd aan de omgeving. Met andere woorden, alvorens een verhaal van start kan gaan, dient het ergens gesitueerd te worden. De diegese (de "wereld" van het verhaal) schept het podium en tegelijkertijd de grenzen van narratieve ontwikkelingen (Kort, 2004: 15). Doorgaans worden deze 
overzichtsbeelden herhaald aan het einde. Nog net voordat de aftiteling verschijnt, zien we Wallander over het strand lopen of Inspector Morse opgaan in de straten van Oxford. Baantjer sluit zelfs letterlijk af met dezelfde beelden als waar het mee begon, met dien verschil dat de ochtend heeft plaats gemaakt voor de nacht.

Uiteraard betreft het hier geen willekeurige selectie beelden. Het 'decor' van de detectives is opgebouwd uit iconen van lokale identiteit. De klokgevels van de grachtenpandjes staan pars pro toto voor Amsterdam. Hetzelfde gaat op voor de uitgestrekte akkers en winterse naaldbossen van Zuid-Zweden, evenals de tuinen, eeuwenoude straatjes en colleges van Oxford (cf. Thomas, 1995: 3). Zelfs de verbeelding van het klimaat speelt hierbij een rol: terwijl de verhalen van Morse zich afspelen onder een blauwe hemel, met af en toe een Engels buitje, wordt de Wallanderserie gekenmerkt door een sobere verlichting, achtervolgingen in de sneeuw en de voor Zweden zo typerende lange schemeringen. De detectives worden aldus gesitueerd in een landschap dat voor de kijker herkenbaar is.

Wat verklaart deze herkenning? Volgens Harvey (1973) heeft ieder mens een geografische verbeelding van de wereld. In ons hoofd dragen we een denkbeeldige kaart van de aarde met ons mee, waarbij we onszelf positioneren ten opzichte van andere streken, landen en werelddelen. In de meeste gevallen hebben we deze plaatsen niet zelf bezocht, maar toch kunnen we ons een bepaald beeld voor ogen halen. Dit beeld verschilt van mens tot mens, maar kent tegelijkertijd een aantal gelijke bronnen, zoals schoolboeken, romans en - niet in de laatste plaats - populaire media. Films, nieuwsuitzendingen, tv-series, stripboeken, games en actualiteitenrubrieken scheppen een beeld van de wereld om ons heen. Miljarden mediagebruikers worden op dagelijkse basis denkbeeldig verplaatst naar locaties waar zij nog nooit zijn geweest, variërend van het Centraal-Amerika van Indiana Jones tot het Tibet van Kuifje (cf. Crouch, Jackson \& Thompson, 2005).

De kracht van geografische verbeelding is dat zij eenheid brengt in iets dat feitelijk geen eenheid kent. Er bestaat niet zoiets als 'het' Centraal-Amerika of 'het' Tibet. Deze locaties worden teruggebracht tot een aantal herkenbare stereotypen, die constant opnieuw ten tonele worden gebracht in diverse media, en zich aldus weten te nestelen in ons gedachtegoed. Indien er sprake is van een positieve stereotypering, zoals in het geval van Amsterdam, Ystad en Oxford, kan zo'n locatie uitgroeien tot een toeristische toplocatie. Binnen toerisme studies wordt dan gesproken van een 'tourist gaze': een gecultiveerde manier van kijken naar een landschap, dat typisch zou zijn voor de 
toerist. Volgens Urry (2002) zijn toeristen constant op zoek naar een beeld dat zij feitelijk reeds in hun hoofd meedragen. De toerist is in die zin vergelijkbaar met een semioticus - hij verzamelt en analyseert beelden (Culler, 1983).

De drie onderzochte tv-detectives maken dankbaar gebruik van de bestaande 'tourist gaze' van Amsterdam, Ystad en Oxford. De karakterschetsen van de centrale personages dienen hierbij ter ondersteuning (cf. Lukinbeal, 2005; Higson, 1996; Schama, 1995; Sydney-Smith, 2006: 84). Dit is met name goed zichtbaar in Wallander. De verbeelding van de eenzame en verlaten akkers van Zuid-Zweden smelt verrassend goed samen met het door eenzaamheid, drankproblemen en een midlifecrisis geteisterde karakter van de detective Kurt Wallander. Op zijn meest eenzame momenten treffen we hem aan op het strand van Ystad, starend naar de zee. Op soortgelijke wijze sluit het cultuurhistorische, academische decor van Oxford naadloos aan op het intellectuele, soms wat snobistische karakter van de Britse rechercheur Morse.

Door het verhaal te situeren in een voor de kijker herkenbare setting, vindt niet alleen een heldere afbakening van de diegese plaats, maar wordt ook de authenticiteit van de serie in zijn geheel verhoogd. De verhaallijnen zijn misschien fictief, maar de gebeurtenissen hadden ook in het echt kunnen gebeuren - letterlijk kunnen plaatsvinden. Deze realistische setting is van essentieel belang voor de centrale thematiek van de onderzochte tv-detectives. De morele vraagstukken die in Morse, Wallander en Baantjer aan bod komen, aangaande de schaduwzijdes van intermenselijk contact, komen sterker uit in een geloofwaardige en herkenbare setting. De drie tvdetectives staan hierin niet op zichzelf. Het plaatsgebonden karakter lijkt een meer algemeen kenmerk te zijn van genre van de detective (cf. McManis, 1978: 320; Cavender, 1998: 87-90). Ter illustratie: het eerste detective verhaal ooit, geschreven door Edgar Allen Poe (1841), was gebaseerd op een straatnaam: Murders in the Rue Morgue.

De tv-detectives maken hierbij niet alleen gebruik van de bestaande 'tourist gaze', maar dragen tegelijkertijd ook iets bij. Binnen toerisme studies wordt, in navolging van Urry (2002), veelal sterk de nadruk gelegd op het visuele karakter van landschapsbeleving. Mijns inziens wordt hierdoor het belang van verhalen en andere non-visuele associaties voor de betekenisgeving van landschap onderschat. Zoals Schama heeft beschreven in Landscape and memory (1995), voelen mensen zich aangetrokken tot bepaalde landschappen, omdat deze landschappen worden vereenzelvigd met specifieke fantasieën, verhalen of herinneringen. Een vergelijkbare stelling wordt ingenomen door 
Jef Malpas in Place and experience (1999). Volgens Malpas ontwikkelen individuen en groepen een beeld van zichzelf en van hun verleden op basis van narratieven, die op hun beurt zijn geworteld in specifieke ruimtes. Narratieve ruimtes vormen, met andere woorden, de basisingrediënten van identiteitsconstructies. De geograaf Yi-Fu Tuan spreekt in dit verband ook wel over 'topophilia': de wijze waarop mensen zich emotioneel verbonden voelen met een bepaald landschap (Tuan, 1974).

In het geval van Morse, Baantjer en Wallander zullen veel kijkers zich betrokken voelen bij de verhaallijnen. Mogelijk identificeren zij zich ook met de lotgevallen van de rechercheurs. Deze persoonlijke betrokkenheid straalt af op de locaties waar de detectives zich afspelen: de betrokkenheid met de personages wordt een betrokkenheid met de wereld waarin deze personages opereren, juist omdat de couleur locale zo belangrijk blijkt te zijn voor de verhaallijn. De verbeelde landschappen worden als het ware geïnjecteerd met narratieve betekenis. Zij groeien uit tot een ankerpunt voor processen van verbeelding en identificatie (cf., Ryan, 1991: 21-23). Aldus bevestigen Inspector Morse, Baantjer en Wallander niet alleen de bestaande tourist gaze, maar maken zij Oxford, Amsterdam en Ystad tevens tot een narratief betekenisvol landschap.

\section{Sporen zoeken}

Het landschap uit de openingsbeelden speelt ook een belangrijke rol gaandeweg elke individuele aflevering. De detectives uit Inspector Morse, Baantjer en Wallander zijn constant op pad, reizend van verdachte naar politiekantoor naar pub naar volgende verdachte. We zien de rode Jaguar van Morse geregeld door het landschap rijden, over landweggetjes en paden, op weg naar de huizen van verdachten of getuigen. Vrijwel identiek zijn de scènes uit Baantjer en Wallander. Het landschap is voor de tv-detective een terrein dat bepaalde geheimen in zich draagt, en dat daarom onderzocht en doorkruist moet worden (cf. Sparks, 1992: 126; Davis, 2001: 137-138). Vergelijkbaar zijn de scènes waarin de rechercheurs er te voet op uittrekken. Hierbij wordt de kijker getrakteerd op een semi-wide shot van het straatbeeld: kletsende studentes die met een boek onder de arm door de smalle straatjes van Oxford wandelen, met op de achtergrond een boekenwinkel of een pub. Of in het geval van Baantjer: fietsers en trams die zich een weg banen door de hectische binnenstad van Amsterdam, langs haringkarren en raamhoertjes. 
Het recherchewerk lijkt, met andere woorden, een onophoudelijke beweging te zijn door de narratieve ruimte. In die zin vertoont de tv-detective een sterke gelijkenis met een bepaalde vorm van toerisme: het rondreizen of trekken. Rondreizigers zijn ook constant op pad. Ze doorkruisen een landschap in huurauto's, treinen of te fiets, op weg van trekpleister tot trekpleister. Van een soortgelijke orde zijn de dagjesmensen, die een stad bezoeken en de dag doorbrengen met het wandelen over straten, langs pleinen en lanen.

Voor deze rondreizigers en dagjesmensen biedt de tv-detective een ideaal aanknopingspunt. De toerist wordt als het ware aan de hand genomen door een bekende inwoner, die kennis heeft van de lokale omstandigheden en toegang verleent tot de plaatselijke geheimen (cf. Tuan, 1985: 57). Wie bijvoorbeeld Ystad bezoekt, kan bij de toeristenbond aldaar een kaartje krijgen met daarop genummerd alle locaties uit de Wallander-films: de plaatsen waar een lijk is gevonden, de favoriete Konditori van Wallander, zijn woonhuis en natuurlijk het politiekantoor. Ook de Wallanderfilmstudio's kunnen worden bezichtigd, waarbij de toerist door de huiskamer en werkkamer van Wallander dwaalt of even plaats mag nemen op de stoel van de rechercheur.

Door nauwgezet de sporen van de personages te volgen, kan het verhaal worden herbeleefd en tegelijkertijd worden aangevuld met informatie uit de werkelijkheid. Kijkers die zich hebben geïdentificeerd met de rechercheurs kunnen nu letterlijk in diens voetsporen treden. De wens om 'dichtbij' een personage te zijn, zal voor veel toeristen een belangrijke rol spelen. Voor enkele toeristen gaat dit verlangen mogelijk nog een stap verder. In een eerdere studie (Seaton, 2002) is gesuggereerd dat sommige vormen van toerisme het karakter van een metempsychose vertonen: een spirituele zoektocht, met als doel om in de huid te kruipen van een ander, charismatisch persoon en zich te vereenzelvigen met diens ziel. Het is niet uitgesloten dat een dergelijk charismatisch persoon een fictief personage zou kunnen zijn (cf. Smith, 2003, geciteerd in: Karakurum, 2006: 25).

\section{Plaats delict}

Bijna elke aflevering van Inspector Morse, Baantjer en Wallander draait om het oplossen van een moordzaak. Dit recherchewerk begint op de plaats delict: op de locatie waar de moord heeft plaats gevonden. Hier verzamelt de detective sporen die hem door de rest van het verhaal zullen loodsen. Deze plaatsen delict nemen in de tours 
ook een belangrijke rol in. Tijdens de Baantjer-tour door Amsterdam wordt bijvoorbeeld uitvoerig stil gestaan bij een nis van de Oude Zuiderkerk, waar in de aflevering 'De Cock en het lijk aan de kerkmuur' een dode zwerver wordt aangetroffen. Deze scène wordt zelfs letterlijk nagespeeld, met medewerking van een Amsterdamse zwerver die is ingehuurd door de organisatie. ${ }^{3}$ Ook tijdens de Inspector Morse-tour en de Wallander-tour worden toeristen rondgeleid langs souterrains, hotelkamers en steegjes, enkel en alleen omdat hier een moord zou hebben plaats gevonden. Wat verklaart de aantrekkingskracht van deze fictieve plaatsen delict? ${ }^{4}$

Op het eerste gezicht lijken de plaatsen delict te sterk van elkaar te verschillen om tot een éénduidig antwoord te kunnen komen. In Wallander worden lijken bijvoorbeeld aangetroffen op het platteland: aan het strand, bij de haven of in een boerderij. De moorden uit Inspector Morse vinden echter veelal plaats in colleges en oude landhuizen. De plaatsen delict van Baantjer tot slot hebben juist een meer moderne, grootstedelijke uitstraling: parkeergarages, filmstudio's, kelders, tunnels en appartementen. In die zin verschilt de enscenering van de moordplaats van serie tot serie.

Wat deze diverse moorden echter met elkaar delen, is het dramatische effect dat plaatsvindt. De moord brengt een scherpe breuk teweeg met het alledaagse leven ter plaatse. Ter illustratie de aflevering 'The Daughters of Cain' van Inspector Morse. In deze aflevering wordt de kijker eerst getrakteerd op een stereotype plaatje van Oxford: studenten roeien op de Thames tijdens een mooie, zomerse dag. Terwijl de boten afmeren, ontdekt een van de studenten een plastic zak, ronddobberend aan de oever, met daarin het lijk van een volwassen man. Het vredige tafereel is plotseling omgeslagen in een plaats delict.

Door het lijk te situeren temidden van het vredige studentenleven van Oxford, het broeierige sfeertje van de Amsterdamse binnenstad of de landelijke rust van het provinciestadje Ystad, wordt enerzijds de couleur locale van deze series als geheel geaccentueerd. "Verdorie, wat is het hier toch mooi!" roept Linda Wallander bijvoorbeeld uit, als zij in de aflevering 'De dekmantel' door het bos loopt, enkele minuten voordat zij een vrachtwagen vol lijken zal aantreffen. Anderzijds biedt deze enscenering de mogelijkheid om de dramatiek van de moord te benadrukken. De wereld staat volledig op zijn kop. Met de komst van de politie en de lijkschouwer wordt de ruimte letterlijk ingenomen. Het roodwitte politielint bakent het plaats delict af van de rest van de omgeving. Daarmee lijkt een cruciale omslag plaats te vinden: het pastorale 
landschap van Oxford en Ystad (of het goedmoedig stoute landschap van Amsterdam) wordt plotseling een 'schuldig landschap'.

De term 'schuldig landschap' is in de jaren zeventig van de vorige eeuw geïntroduceerd door de Nederlandse kunstenaar en schrijver Armando (1921-). Armando bracht zijn jeugd door in de omgeving van kamp Amersfoort, dat tijdens de Tweede Wereldoorlog dienst deed als 'Polizeiliches Durchgangslager'. Wat Armando na de oorlog verbaasde, en wat hem tijdens zijn carrière als kunstenaar blijvend heeft beïnvloed, was het feit dat dit voormalige oorlogsgebied een dergelijk vredige uitstraling had gekregen. Het leek wel of de moorden en martelingen nooit hadden plaats gevonden, zo welig tierde het natuurschoon hier. Maar de bossen rondom het concentratiekamp waren getuige geweest van gruwelijke oorlogsmisdaden, aldus Armando, en waren daar mede schuldig aan. Ze vormden, met andere woorden, een 'schuldig landschap' (Armando, 1998).

De kracht van de term 'schuldig landschap', is dat landschappen zelf een actieve rol krijgen toegedicht. Landschappen kunnen - net als mensen - een bepaalde schuld met zich meedragen. Dat lijkt op het eerste gezicht tegenstrijdig met het gezonde verstand. Landschappen worden doorgaans gezien als een ontvangende partij, of als iets dat bedwongen dient te worden. Door ruimte echter zo'n actieve rol toe te dichten, sluit Armando aan op een filosofische stroming die weliswaar nooit centraal heeft gestaan, maar toch al lange tijd deel uitmaakt van het Westerse gedachtegoed. Diverse filosofen, van Heidegger tot Merleau-Ponty, hebben gewezen op het belang van plaats voor de beleving en waarneming van de werkelijkheid (Malpas, 1999: 1-18). Gebeurtenissen vinden plaats, omdat ze ergens plaats kunnen vinden, omdat er een ruimte is van waaruit de gebeurtenis tot stand kan komen. Zelfs de meest abstracte fantasieën en filosofieën staan nooit los van de fysieke werkelijkheid, zo wordt beredeneerd door Marcia Cavell (1993: 41). Zij ontstaan en wortelen altijd ergens: "in the only place it can, here, in the midst of things".

Dat landschappen een actieve rol kunnen spelen in de wijze waarop de mens de werkelijkheid beleeft, wil nog niet zeggen dat ieder landschap even belangrijk is. Sommige landschappen of ruimtes lijken meer 'actief' te zijn dan andere. De kracht van een landschap komt bijvoorbeeld duidelijk aan de oppervlakte bij gebeurtenissen die een negatieve associatie oproepen. Hierbij kan gedacht worden aan oude oorlogsgebieden, zoals kamp Amersfoort, of aan locaties waar grote rampen of 
verkeersongelukken hebben plaats gevonden. Alhoewel er vaak nog weinig materiële referentiepunten zijn aan het verleden, zal deze plaats voor de nabestaanden en andere betrokkenen altijd een belangrijke, mogelijk zelfs traumatische betekenis houden (cf., Harrison, 2005).

Ook fictieve verhalen over gruwelijke moorden of ongelukken kunnen een plaats actief maken. Binnen de Westerse volkscultuur bestaat bijvoorbeeld een lange traditie van legendes over 'behekste' ruimtes: verlaten huizen, kelders, kerkhoven of meren die een eigen, kwaadaardige wil zouden hebben (Ellis, 1989). ${ }^{5}$ Deze narratieve traditie is terug te vinden in de literatuur (Hausladen, 2000) en meer recent ook in film en televisie. Het zijn dit soort verhalen die door grote groepen mensen worden beluisterd, doorverteld en herinnerd, die de basis vormen voor de activiteit van een landschap.

Het is hierbij nog maar de vraag, of het onderscheid tussen fictie en werkelijkheid zo'n grote rol speelt in de belevingswereld van veel mensen (cf. Herbert, 1996). Sterker nog: de liminaliteit tussen fictie en werkelijkheid lijkt juist onderdeel te vormen van de aantrekkingskracht van deze locaties. In het geval van Baantjer kan bijvoorbeeld worden opgemerkt, dat veel van de afleveringen van deze detective zijn gebaseerd op waargebeurde zaken, die de auteur Appie Baantjer tijdens zijn langdurige loopbaan als rechercheur heeft meegemaakt. Tijdens de Baantjer-tour wordt ook geregeld ingegaan op de achtergrond van de auteur, en worden constant verbanden gelegd tussen fictieve en daadwerkelijke moordzaken, zoals de moord op Chinese Annie en Magere Josje. Hierbij wordt de 'werkelijkheid' niet alleen ingezet om het authentieke karakter van de tv-detective te benadrukken. Er lijkt veeleer sprake te zijn van een wederzijdse versterking. De werkelijkheid wordt ook meer aansprekend en inzichtelijk gemaakt door de verhalen die er mee samen hangen.

\section{Conclusie}

In dit artikel is getracht om een inhoudelijke verklaring te vinden voor de populariteit van de tv-detective tour. Onderzocht werd welke narratieve kenmerken van de tvdetective een stimulans vormen om de locaties te gaan bezoeken. Daartoe werd een tekstuele analyse verricht van drie populaire tv-series uit verschillende taalgebieden binnen Europa, die stuk voor stuk hebben geleid tot aanzienlijke toeristenstromen: Baantjer, Inspector Morse en Wallander. Gesteld werd dat een dergelijke analyse niet een sluitende verklaring kan bieden voor de populariteit van media tours, maar dat zij 
wel een aanvulling vormt op reeds bestaande studies, waarin de media-inhoud slechts een summiere rol speelt.

Geconcludeerd kan worden dat de toeristische aantrekkingskracht van de tv-detective mede voortkomt uit het feit dat plaats en beweging een belangrijke rol vervullen in de narratieve structuur van dit genre. Meer in het bijzonder zijn het drie narratieve kenmerken die de lust tot reizen opwekken. Ten eerste blijkt de couleur locale een belangrijke rol te spelen in de tv-detective, meer nog dan bij enig ander genre. Tijdens de openingsbeelden worden de onderzochte detectives gesitueerd in een voor de kijker herkenbaar landschap: Baantjer in de rosse buurt van Amsterdam, Inspector Morse in het elitaire Oxford en Wallander in de verlaten velden van Zuid-Zweden. Iconen van regionale identiteit worden herhaald om het sociaal-realistische gehalte van de serie te verhogen. Aldus sluiten de tv-detectives aan op de bestaande 'tourist gaze' van deze steden. Tegelijkertijd dragen ze hier ook iets aan bij. De verbeelde landschappen worden door de tv-series geïnjecteerd met narratieve betekenis. Dit maakt de steden Oxford, Amsterdam en Ystad tot niet alleen een herkenbaar, maar tevens tot een betekenisvol landschap. Een algemene les die hieruit getrokken kan worden, is dat visuele en narratieve betekenislagen op een meer complexe wijze met elkaar samenhangen dan doorgaans wordt verondersteld in het werk van onder meer John Urry (2002).

Ten tweede speelt het verbeelde landschap een belangrijke rol in de narratieve ontwikkeling van elke individuele aflevering. Om de moordzaken te kunnen oplossen, zijn de rechercheurs uit Baantjer, Inspector Morse en Wallander onophoudelijk in beweging. Ze trekken rond van verdachte naar pubs naar politiekantoor naar volgende verdachte. Deze constante beweging door de narratieve ruimte vindt zijn weerklank in de activiteiten van de toerist. Rondreizigers en dagjesmensen zijn immers ook constant op pad. Reizen is voor hen bovenal een kinesthetische ervaring, gebaseerd op lichamelijke voortbeweging. Door hierbij de tv-detective als uitgangspunt te nemen, ontvouwt zich een logische route om de stad of streek te verkennen. De toerist treedt letterlijk in de voetstappen van zijn geliefde rechercheur en doorkruist de lokale gemeenschap, op zoek naar aanwijzingen of sporen. De intimiteit is voelbaar, want achter elke hoek kan plots de rechercheur opdoemen. Of mogelijk is de toerist - in een extreme vlaag van metempsychose - zélf de rechercheur geworden. 
Tot slot wordt de tv-detective gekenmerkt door een obsessie met het stoffelijke. Elke individuele aflevering heeft als vertrekpunt een plaats delict, van waaruit het sporenonderzoek wordt opgestart. Deze plaatsen worden in Inspector Morse, Wallander en Baantjer doorgaans gerepresenteerd als alledaagse locaties, die door de vondst van een lijk slaan deze locaties plots om in een macabere tegenwereld. De toerist heeft de mogelijkheid om deze locaties zelf te bezoeken en aldaar, vanuit een veilige positie, kennis te maken met het schuldige landschap van de tv-detective.

Afsluitend kan worden gesteld dat de onderzochte locaties een complex verbindingspunt vormen tussen de diegetische wereld van de televisie en de 'echte' wereld daarbuiten. Ook de lotgevallen van de acteurs kunnen hierbij een rol spelen. Tijdens de Inspector Morse-tour wordt bijvoorbeeld uitvoerig stil gestaan bij het vermeende alcoholisme van de acteur John Thaw, een ironisch gegeven gezien het feit dat pubs een centrale rol spelen in het door een biermerk gesponsorde Inspector Morse. Op vergelijkbare wijze speelt het persoonlijke leven van Johanna Sällström, de actrice die de rol van Linda Wallander vervulde, een rol tijdens de Wallander-tour. Door melding te maken van het treurige feit van haar zelfdoding in 2007, slaat de gids een brug tussen de werkelijkheid en de melancholische sferen uit Wallander. Dit soort verhalen maken de plaatsen delict uit Baantjer, Inspector Morse en Wallander tot een aantrekkelijke locatie, juist omdat ze zo aangrijpend zijn. Voor even bevindt de toerist zich in een intrigerend schemergebied - een spanningsveld tussen fantasie en werkelijkheid, tussen het geestelijke en het stoffelijke. 


\section{Noten}

1. Dit artikel wordt gefinancierd door de Nederlandse Organisatie voor Wetenschappelijk Onderzoek (NWO), binnen het kader van de VENI Vernieuwingsimpuls. Dank gaat verder uit naar Liesbet van Zoonen, Gerard Rooijakkers, Linda Duits, Floris Muller, Elvire Jansen en Bas van Druijten voor feedback op eerdere versies van dit artikel.

2. Geselecteerd zijn 'The Way through the Woods', 'The Daughters of Cain', 'Chercubim and Serafin', 'Day of the devil', 'Deadly slumber', 'Twilight of the Gods' (Inspector Morse), 'Het zwakke punt', 'De fotograaf', 'De dekmantel', De kasteelruïnes', 'Bloedbanden', 'Het Geheim' (Wallander), 'De Cock en de moord op het bureau', 'De Cock en de reclamemoord', 'De Cock en de motorclubmoord', 'De Cock en de moord in het Kremlin', 'De Cock en de moord op de wallen', 'De Cock en de moord uit angst' (Baantjer).

3. Feitelijk betreft het hier een vorm van 'ostension': het naspelen of uitvoeren van verhalen in de werkelijkheid (Ellis, 2001).

4. De toeristische aantrekkingskracht van plaatsen delict is eerder opgemerkt door onder andere Rojek (1993b: 137-145) en Lennon \& Foley (2000), maar hierbij betrof het wel steeds waargebeurde (zelf-) moorden.

5. Dat ook spookhuizen een toeristische aantrekkingskracht hebben, blijkt onder meer uit het bestaan van 'Haunted Hotel Guides'. Zie bijvoorbeeld www.hauntedhotelguide.com voor een overzicht van behekste hotels, kastelen en herbergen in de UK. 


\section{Literatuur}

Adams, G. (2007). Morse: the no.1 gentleman detective. The Independent, 27/04/2007. Armando (1998). Het schuldige landschap. Amsterdam: Voetnoot.

Baudrillard, J. (1981). Simulacres et simulation. Paris: Galilée.

Beeton, S. (2005). Film induced tourism. Clevedon: Channel View Publications.

Betz, P.M. (2006). Lesbian detective fiction: woman as author, subject and reader. Jefferson: McFarland.

Brooker, W. (2005). The Blade Runner Experience: Pilgrimage and Liminal Space. In W. Brooker (Ed.), The Blade Runner Experience (pp. 11-30). London: Wallflower.

Brooker, W. (2007). Everywhere and nowhere: Vancouver, fan pilgrimage and the urban imaginary. International Journal of Cultural Studies, 10, nr. 4, 423-444.

Cavell, Marcia (1993). The psychoanalytic mind. From Freud to philosophy. Cambridge: Harvard University Press.

Cavender, Gray (1998). In 'The shadows of shadows': television reality crime programming. In M. Fishman \& G. Cavender (Eds.) Entertaining crime. Television reality programs (79-94). New York: Aldine de Gruyter.

Cohen, J. (1986). Promotion of overseas tourism through media fiction. In W.B. Joseph \& L. Moutinho (Eds.) Tourism services marketing: advances in theory and practice (pp. 229-237). Cleveland: American Marketing Association and Cleveland State University.

Couldry, N. (2000). The place of media power. Pilgrims and witnesses of the media age. London: Routledge.

Craig, P.R. (1998). Character and locale in crime fiction. Writer, 111, nr. 5, 13-15.

Crouch, D., Jackson, R. \& Thompson, F. (2005). The media and the tourist imagination: converging cultures. London: Routledge.

Culler, J. (1981). Semiotics of tourism. American journal of semiotics, 1, 1, 127-140.

Davis, H. (2001). Inspector Morse and the business of crime. Television \& new media, 2, $n r .2,133-148$.

Deleuze, G. \& Guattari, F. (1988). A thousand plateaus: capitalism and schizophrenia. London: Athlone Press.

Edensor, T. (2005). Mediating William Wallace. Audio-visual technologies in tourism. In D. Crouch, R. Jackson \& F. Thompson (Eds.), The media and the tourist imagination: converging cultures (pp. 105-118). London: Routledge. 
Ellis, B. (1989). Death by folklore: ostension, contemporary legend, and murder. Western Folklore, 48, 201-220.

Ellis, B. (2001). Aliens, ghosts, and cults. Legends we live. Jackson: University Press of Mississippi.

Gibson, S. (2006). A seat with a view. Tourism, (im)mobility and the cinematic-travel glance. Tourist Studies, 6, nr. 2, 157-178.

Gramsci, A. (1985). Antonio Gramsci: selections from cultural writings. Cambridge (Mass.): Harvard University Press.

Hardyment, C. (2000). Literary trails: British writers in their landscapes. London: National Trust.

Harrison, R.P. (2005) The dominion of the dead. Chicago: The University of Chicago Press.

Harvey, D. (1973). Social justice and the city. Londen: Arnold.

Hausladen, G. (2000). Places for dead bodies. Austin: University of Texas Press.

Hausladen, G. (1996). Where the bodies lie. Sense of place and police. Journal of Cultural Geography, 16, nr. 1, 45-63.

Herbert, D. (1996). Artistic and literary places in France as tourist attractions. Tourism management, 17, $n$ r. 2, 77-85.

Higson, A. (1996). Space, place, spectacle: landscape and townscape in the "Kitchen Sink" film. In A. Higson (Ed.), Dissolving views. Key writings on British cinema (pp. 133-157). Londen: Cassell.

Iwashita, C. (2006). Media representations of the UK as a destination for Japanese tourists: popular culture and tourism. Tourist Studies, 6, nr. 1, 59-77.

Karakurum, D. (2006). Cracking The Da Vinci Code: an analysis of The Da Vinci Code tourist phenomenon. Breda: NHTV Breda University.

Knight, S. (1980). Form and ideology in crime fiction. London: Macmillan

Knight, S. (2004). Crime fiction, 1800-2000: detection, death, diversity. Basingstoke: Palgrave Macmillan.

Kort, W.A. (2004). Place and space in modern fiction. Gainesville: University Press of Florida.

Lennon, J. \& Foley, M. (2000). Dark tourism. Londen: Continuum.

Lukinbeal, C. (2005). Cinematic landscapes. Journal of Cultural Geography, 23, nr.1, $3-22$. 
Malpas, J.E. (1999). Place and experience: a philosophical topography. Cambridge: Cambridge University Press.

Mandel, E. (1984). Delightful murder: a social history of the crime story. London: Pluto.

Markozwitz, J.A. (2004). The gay detective novel. Lesbian and gay main characters and themes in mystery fiction. Jefferson: McFarland \& Co.

McManis, D.R. (1978). Places for mysteries. Geographical review, 68, nr. 3, 319-334.

Mordue, T. (2001). Performing and directing resident/tourist cultures in Heartbeat country. Tourist Studies 1, nr. 3, 233-252.

Mukherjee, U.P. (2003). Crime and empire: the colony in nineteenth-century fictions of crime. Oxford: Oxford University Press.

Munt, S.R. (1994). Murder by the book? Feminism and the crime novel. London: Routledge.

Poe, E.A. (1841) .The murders in the Rue Morgue. In Graham's Magazine 18, 166179.

Pyrhönen, H. (1994). Murder from an academic angle: an introduction to the study of the detective narrative. Columbia: Camden House.

Reijnders, S.L. (2010) Op het spoor van 007. Plaatsen van verbeelding in de wereld van James Bond (work in progress).

Riley, R. \& C. van Doren (1992) Movies as tourism promotion: a 'pull' factor in a 'push' location. Tourism management: research, policies, planning 13, nr. 3, 267274.

Reitz, C. (2004). Detecting the nation. Fictions of detection and the imperial venture. Columbus: The Ohio State University Press.

Rojek, C. (1993a). Indexing, dragging and the social construction of tourist sights. In C. Rojek \& J. Urry (Eds.), Touring cultures. Transformations of travel and theory (pp. 52-73). Londen: Routledge.

Rojek, C. (1993b). Ways of escape. Modern transformations in leisure and travel. Basingstoke: Macmillan

Roosendaal, J.C. (2002). Moord achter de duinen. In J.C. Roosendaal, B. Vuijsje \& C. Rippen (Eds.), Moorden met woorden. Honderd jaar Nederlandstalige misdaadliteratuur (pp. 19-45). Den Haag: Biblion.

Ryan, Marie-Laure (1991). Possible worlds, artificial intelligence, and narrative theory. Bloomington: University of Indiana Press. 
Schama, S. (1995). Landscape and memory. New York: Knopf.

Seaton, A.V. (1998). The history of tourism in Scotland: approaches, sources and issues. In R.MacLellan \& R. Smith (Eds.), Tourism in Scotland (pp. 1-41). London: International Thompson Business Press.

Seaton, A.V. (2002). Tourism as metempsychosis and metensomatosis: the personae of eternal recurrence. In Dann, G. (Ed.), The tourist as a metaphor of the social world (pp. 135-168). New York, CAB International.

Siegel, J. (1993). The American detective: an illustrated history. Dallas: Taylor.

Smith, M. (2003). Issues in cultural tourism studies. Londen: Routledge.

Sparks, Richard (1992) Television and the drama of crime: moral tales and the place of crime in public life. Buckingham: Open University Press.

Sydney-Smith, S. (2006). Changing places: touring the British crime film. Tourist Studies 6, nr. 1, 79-94.

Symons, J. (1992). Bloody murder. From the detective story to the crime novel: a history. London: Papermac.

Thomas, L. (1995). In love with Inspector Morse: feminist subculture and quality television. Feminist Review 51, nr. 1, 1-25.

Torchin, L. (2002). Location, location, location. The destination of the Manhattan TV Tour. Tourist Studies 2, nr. 3, 247-266.

Tuan, Y. (1974). Topophilia: a study of environmental perception, attitudes, and values. Englewood Cliffs: Prentice-Hall.

Tuan, Y. (1985). The landscapes of Sherlock Holmes. Journal of Geography 84, nr. 2 , 56-60.

Tzanelli, R. (2004). Construction the "cinematic tourist". The "sign industry" of the Lord of the Rings. Tourist Studies 4, nr. 1, 21-42.

Urry, J. (2002). The tourist gaze: leisure and travel in contemporary societies. London: Sage.

Watson, N.J. (2006). The literary tourist. Readers and places in Romantic \& Victorean Britain. Basingstoke: Palgrave Macmillan.

Wheeler, T.B. (2003). Finding Sherlock's London. Travel guide to over 200 sites in London. Londen: iUniverse. 
Stijn Reijnders

Watching the detectives. Inside the guilty landscapes of Inspector Morse, Baantjer and Wallander

Visiting the settings of popular media products has become a growing niche within the tourist market. This paper provides a content-based explanation for the popularity of one specific example: the TV detective tour. Three popular TV series from different linguistic regions of Europe were analysed, each of which has led to substantial tourist numbers: Inspector Morse (Oxford), Wallander (Ystad), and Baantjer (Amsterdam). The results show that the tourist attraction of the TV detective programme is due in part to its topophilic character. First, 'couleur locale' is extremely important to the narrative setting of the detective programmes; the narratives elaborate on existing tourist gazes. Second, the narrative development is characterised by a process of investigation and tracking. By taking the tour, viewers can walk in the detective's footsteps and relive the storylines. Finally, the TV detective genre promises the viewer/tourist an acquaintance with the thrilling, 'guilty' landscapes of the TV detective.

Keywords: detective, popular culture, television, fiction, place, landscape, cultural tourism 